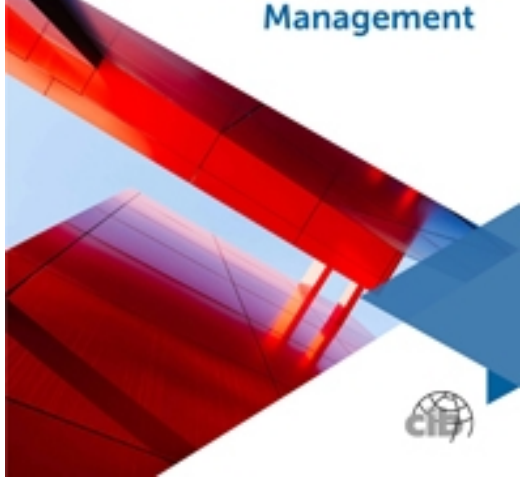

\title{
Climate, Buildings' Envelope Design and Energy Patterns: Improving Energy Performance of New Buildings in Kuwait
}

\begin{tabular}{|r|l|}
\hline Journal: & Engineering, Construction and Architectural Management \\
\hline Manuscript ID & ECAM-04-2021-0360.R2 \\
\hline Manuscript Type: & Original Article \\
\hline Keywords: & $\begin{array}{l}\text { Building Information Modelling, Decision Support Systems, Design, } \\
\text { Simulation }\end{array}$ \\
\hline Abstract: & \\
\hline \multicolumn{2}{|c}{} \\
\hline
\end{tabular}

\section{SCHOLARONE ${ }^{\text {m }}$ \\ Manuscripts}




\title{
Climate, Buildings' Envelope Design and Energy Patterns: Improving Energy Performance of New Buildings in Kuwait
}

\begin{abstract}
Purpose - The two main contributing factors that control the overall buildings' energy performance are the Heating Ventilation and Air Conditioning (HVAC) system and the envelope design. Environmental design guidelines that consider these two factors aim to lower the energy consumption. However, they are regional and climate sensitive. Three main building envelop design variables are investigated (orientation, compactness, and window to wall ratio) to identify their impact on the overall building's energy consumption within Kuwait's regional and climate conditions.
\end{abstract}

Design/methodology/approach - The energy consumption rates of typical shaped buildings are simulated while varying their geometry between a square to a rectangular floor plan. The analyse quantifies the associated energy usage, and provide early stage envelope design guidance specific to the country's conditions, to make informed decisions toward environmentally conscious buildings.

Findings - The analysed envelope variables have the potential to reduce energy consumption by $40 \%$, and the possibility to reduce HVAC system capacity by $30 \%$. In contrast to the general guidance in literature and standards, the simulation results demonstrate that less compact building forms perform on occasions better than the most compact ones.

Originality/value - The objective of this paper is to quantify the energy consumption rates for buildings located within the Arabian Peninsula, an under-studied region with potentially high interest considering three main envelope design variables. The buildings' yearly energy consumption patterns are unique and suggest different envelope design considerations, compared to other regions with different climate conditions. This emphasises on the importance of regional guidance for the different factors associated with energy and buildings' environmental performance.

\section{Introduction}

At the early design stage of any building project, the designing team collectively decides on the different engineering components of the project, such as the building's structure, material, operating and control systems, following the user's requirements and the project's budget (Tiene et al., 2018). Building designers asses those components during the design stage, and when they have options (design variables), their evaluation extends further than the isolated performance of a single variable selection, and considers the impact of one variable on another (Fesanghary et al., 2012). The design variables are analysed and their performances are measured, given their financial (such as investment cost and operational costs) and non-financial (such as user satisfaction and environmental) impacts (Nguyen et al., 2014).

Designers make their selection of materials and systems based on specific objectives. Design objectives can be categorised as performance oriented, such as focusing on energy efficiency or user satisfaction; or financial, concerning construction resources and operational costs. The selection takes in to account the location's climate and the natural geographical challenges, such as soil quality and area topography. Availability of resources is also a major factor in defining the design objectives, 
especially the financing limitations, the availability of construction materials and the national/international regulations, specific for building projects.

From over 70 publications reviewed in (Huang and Niu, 2016), 82.2\% of the studies aimed to reduce the building's energy consumption or it's life cycle cost (such as those in (Budaiwi and Abdou, 2013; Fong et al., 2006; Hamdy et al., 2011)); 12.3\% of the studies focused on building's visual comfort (such as those in (Cassol et al., 2011; Delgarm, Sajadi, Delgarm, et al., 2016; Lartigue et al., 2014)) and $5.5 \%$ focused on the thermal comfort within the building's envelop (such as those in (Delgarm, Sajadi and Delgarm, 2016; Yu et al., 2015)). The majority of studies focused on the HVAC system design variables than the envelop design (Huang and Niu, 2016). This is partly due to the limited number of engineering components in HVAC system design compared to the large number of engineering components within the buildings' envelop design, directly and indirectly impacting the building's energy performance. Building materials, as an example of building envelope design components, consist of hundreds of variables including but not limited to selecting the structural system, insulation, plumbing, cladding, and finishing materials. Every envelope design variable has its own complex effect on the heat transfer process between the atmosphere and the inside of buildings.

While several studies examine and aim to improve buildings performance considering the HVAC systems design/operation in Kuwait (Budaiwi and Abdou, 2013; Elkilani and Bouhamra, 2001; Park et al., 2019; Sebzali and Rubini, 2007), to the best knowledge of the authors, studies on building's envelop design and its influence on the energy consumption is missing from literature within that region. This paper aims to fill this gap by focusing on Kuwait's climate and regional conditions on the energy performance of buildings, examining three specific buildings envelop design variables (orientation, compactness and window to wall ratio). The findings aim to provide important initial envelope design considerations to minimise the building's energy consumption.

\section{Buildings energy consumption and envelope design}

Literature is absent in investigating the effect of buildings envelop design variables on the building's energy requirements within the Gulf Cooperation Council (GCC) region. First, Kuwait's regional and climate conditions are presented. Second, a review of the existing literature in different regions, where influence of climate and regional conditions on envelope design and energy consumptions, are investigated. The review takes into account studies analysing design variables such as shape, geometry, orientation, envelope composition and material specifications. The objectives in these studies are mostly focused on simulating different buildings' energy consumption, identify potential energy saving designs, based on the specific regional climate influences.

\subsection{Kuwait regional and climate conditions}

Kuwait is located at the Northeast corner of the Arabian Peninsula (Figure-1), and shares borders with KSA and Iraq. Kuwait has an arid climate, generally known for its very long and hot summers, with average temperatures ranging from 38 to $46^{\circ} \mathrm{C}$ and occasional days when temperatures reach over $50^{\circ} \mathrm{C}$. It also lacks rainfall, with an average of 22 wet days a year and a mean annual rainfall of $119 \mathrm{~mm}$. During summer, hot winds blow from the Northwest (locally known as "Shamal") dominating about $60 \%$ of the total wind directions (Al-Awadhi and AlShuaibi, 2013). To understand the national significance of buildings on energy performance, Figure-2 (using Global Energy Market Research data (Enerdata, 2017a, 2017b, 2017c, 2018a, 2018b, 2018c)) summarises the electricity consumption distribution within the GCC region. Between the residential, industrial and services sectors, the residential sector within the GCC dominates most of the electricity consumption in four out of the six countries. The residential sector mostly consists of buildings and their energy consumption mostly attributed toward HVAC utilities. For Kuwait, $65 \%$ of the electricity is consumed by the residential sector (mostly buildings). Furthermore, significant portion of the electricity consumed by the industrial and services sectors is attributed to buildings as well, needed to operate those sectors. This 
makes the buildings cumulative energy consumption exceed $70 \%$ of total electricity generated (Enerdata, 2017c).

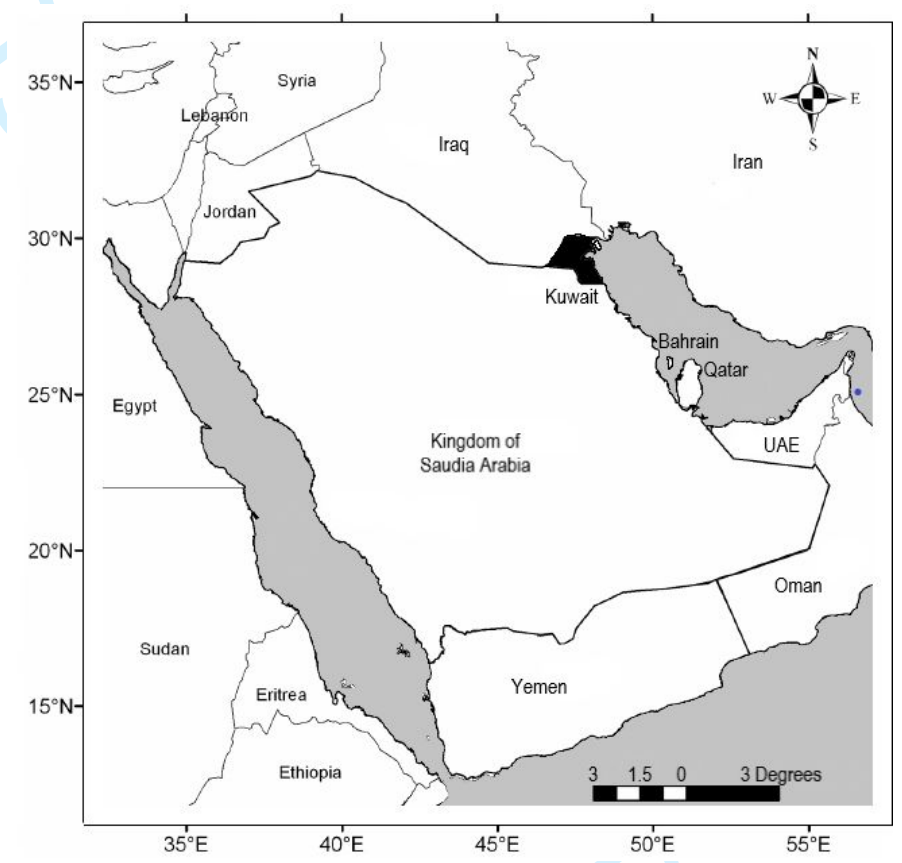

Figure 1 - The Arabian Peninsula - Kuwait shaded in Black

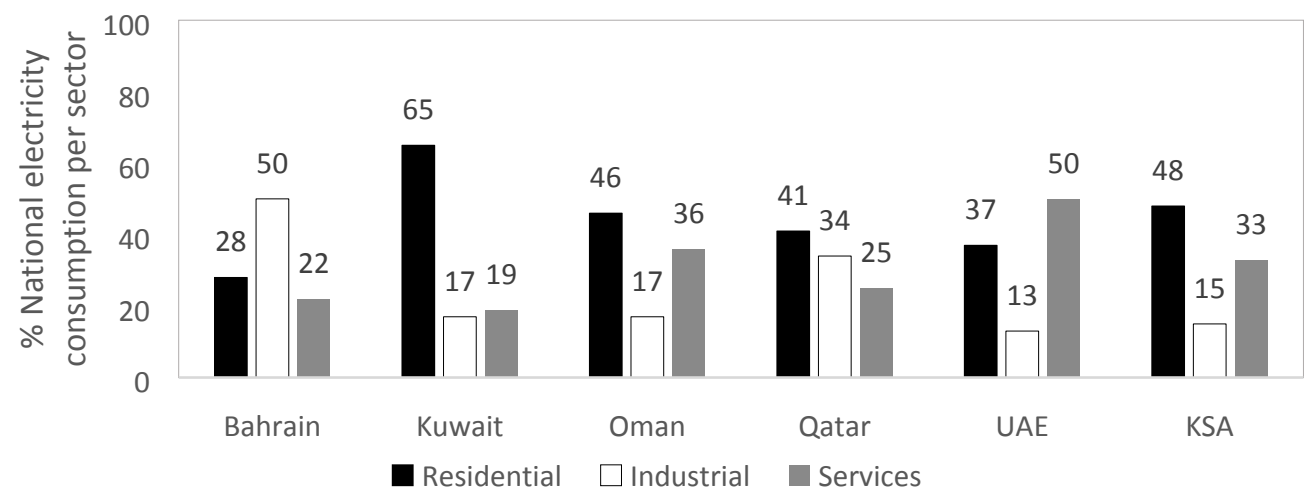

Figure 1 - GCC electricity consumption distribution summary, compiled from (Enerdata, 2017b, 2017a, 2017c, 2018a, 2018c, 2018b)

\subsection{Regional studies on Envelop Design variables and Buildings' Energy Performance}

Most of the studies that have analysed the energy performance of buildings use case studies around the world to explain the specific regional climate influence on different envelop design variables. Given the implications of the regional conditions on the results, details of their outcomes are broken down based on the weather characteristics in Europe, Australia, and Asia.

In Europe, the effect of walls, ceilings, roof, windows and shading characteristics, as envelop design variables, on energy performance are investigated in (Baglivo et al., 2017). The results discussed in their study are specific to the case of a new residential buildings, located in Italy. It emphasises on the effect of a location's specific climate being the main deriving element in the design stage process. Their findings were that on one hand, in colder seasons, insulation and variables controlling the building's air tightness (such as windows) have more influence on the building's thermal behaviour, 
maintaining the indoor designed comfort levels. On the other hand, in warmer weather, solar radiation and heat gains are leading to internal thermal overheating; Therefore, walls, windows and shading are the variables controlling the energy performance.

A trade-off between lowering the energy and the user's comfort in the building was the objective in (Ferrara et al., 2015). The different elements of the envelop design, defined as variables, are the Wall/Roof/ceiling construction typology, glazing characteristics, thickness of external insulation on external walls/roof, dimensions of glazed area, depth of overhang and vertical fin shading system. The case study is the design of a school classroom in Northern Italy. The output from the model quantifies buildings' energy consumption increase, corresponding to the amount of solar gains, penetrating the envelop during the different seasons. The model is created to optimise the envelope variables according to the user's input data. The limitation with this model is that it requires predesigned elements, set as user inputs, such as the overall geometry and orientation of the building. This works optimally in the cases of standard building designs, when the user cannot request a change in geometry, but can alter the materials used.

In Australia, the wall materials' layering effect on the thermal performance of buildings is analysed in (Albatayneh et al., 2018). The model also considers enhancing the energy performance by integrating in-site renewable energy systems. It calculates which combination of wall layers can provide the greatest energy savings with the least cost of material. To run the simulation using this module, the user needs to input the geometry design parameters (dimensions and orientation) as well as the weather file of the selected region. The output would be of a great value when multiple design elements are decided, and remaining is the selection of wall profile, complemented by the suggestion to use a photovoltaic energy generation system as an energy and cost-effective package. Their case study fits that description, as their model is developed to optimise full scale housing modules in Australia; limiting the use of their methodology from being applied at different regions.

The buildings' orientation, number of floors, window to wall ratio, and glazing material specifications are the variables analysed in (Gero et al., 1983). The model is created to find designs that can reduce the amount of energy consumed, as well as the building's capital cost, while increasing the usable area. The results from the case study (weather input of Sydney, Australia) show that the range of thermal load ratio is at its lowest for buildings with a single floor design. On the contrary, as the number of floors increases, the thermal load increases, compared with buildings of similar gross area. The study also concludes that the building's envelop parameters have higher effect on the thermal load than they have on either capital cost or usable area. The flexibility in comparing vertical buildings to horizontal buildings (with similar build-up area) depends on the construction location. The optimum designs will differ based on the user's definition of the area and the specific restrictions of its location.

The simulation model in (Marks, 1997) is built to analyse the energy performance of buildings with constant volumes and heights. The aim is to optimise the energy performance, while varying the shape and orientation of the envelope design. The model focuses on minimising the buildings' capital cost (materials and construction) and the yearly heating cost. The results indicate that the optimum shape is highly dependent on the data input, especially the regional climate. The optimum shape varies from a regular octagon in regions with short heating periods to a polygon with fewer sides in regions with longer heating periods. The module users must consider that the definition of shape and the range of its variance can result in building forms that are atypical for construction or complex in maximising internal area usage.

In Asia, the impact of buildings' geometry, varying the form and shape in the design process, on energy patterns is investigated (Rashdi and Embi, 2016). The aim is to find the building's form and shape that can reduce the heat gain, and eventually lower the cooling load. The building's form and shape are mostly influenced by the solar energy it receives, based on the envelope's surface area exposed to it, that impact its energy consumption. The geographically specific results, based on the 
weather characteristics of Malaysia, indicate that the more compact a building form is (lower surface area to volume ratio), the better energy performance it achieves. It's reported that most of the commercial office building's cooling systems consume (in average) about $70 \%$ of yearly total energy consumption in Malaysia (similar to Kuwait's); The output of the simulation module in the study shows that the selection of an optimum form, orientation, and envelope configuration has the potential to reduce the building's energy consumption by almost $40 \%$. This research is a great example for providing regional guidance at the early stage of buildings' design considering their selected variables. The concern in comparing different shapes in this model is that it does not consider the variance in construction materials' quantities, as well as the wasted floor areas formed within shape corners different than the typical 90-degree angle between walls.

The regional impact of orientation, window sizing and the design of overhangs (the structural installation on top of windows designed to provide shade) on buildings' energy consumption is the focus in (Delgarm, Sajadi and Delgarm, 2016). The model is designed to find optimum buildings with minimum energy loads, exerted for cooling/heating, and minimum energy loads exerted for lighting. The model was used to compare the results from four cities in Iran, with distinct climate characteristics, cold, temperate, warm-dry, and warm-humid. The model suggested a slightly different orientation for each region. The optimum overhang design specifications are almost similar, regardless of the climate variance. As for the window sizing, the optimum design within the colder region had larger widows. The results indicate that optimum window sizes get smaller in size as the regions get warmer. Geometry of buildings in this model is a user input and cannot be optimised. However, the model was able find an optimum design in each region, with significant improvements from the initial input design.

The buildings' envelope analysis in (Aksoy and Inalli, 2006) compared only two floor area shapes, a square form and a rectangular form with an aspect ratio of 2:1, under the relatively cold climate of Elazig, Turkey. Their analysis demonstrates that the square shape design facing the North/East has the least energy consumption levels. The conclusion that a more compact form result in better energy performance found to be similar to (Rashdi and Embi, 2016), even though the climates simulated were extremely different. The results indicate that the compact form perform better, comparing the energy simulation outputs of buildings' HVAC consumption rates.

\subsection{Buildings' Energy Simulation Platforms}

The results of Energy simulation platforms have been tested by several studies, and the reliability on their performance was assessed (Zhou et al., 2014, 2008). The reliability of results from simulation models depends on the quality and accuracy of input data (Dodoo et al., 2017) as well as modellers' experience (Choi, 2017; Imam et al., 2017; Mirsadeghi et al., 2013; Simões et al., 2014; Ward et al., 2016).

20 different energy simulation software and their capabilities are evaluated in (Crawley et al., 2008). Table 1, summarises the diverse potentials from those reported simulation platforms. Not to argue that having a wide range of features and functions lead to a better platform; some of the less diverse simulation programs can have more specific focus on a certain energy/performance aspect, able to produce more accurate results related to that specific part. However, EnergyPlus and IES are in the lead when looking for a wholesome single platform that is able to factor in different aspects of energy parameters. 
Table 1 -Capabilities of energy simulation platforms

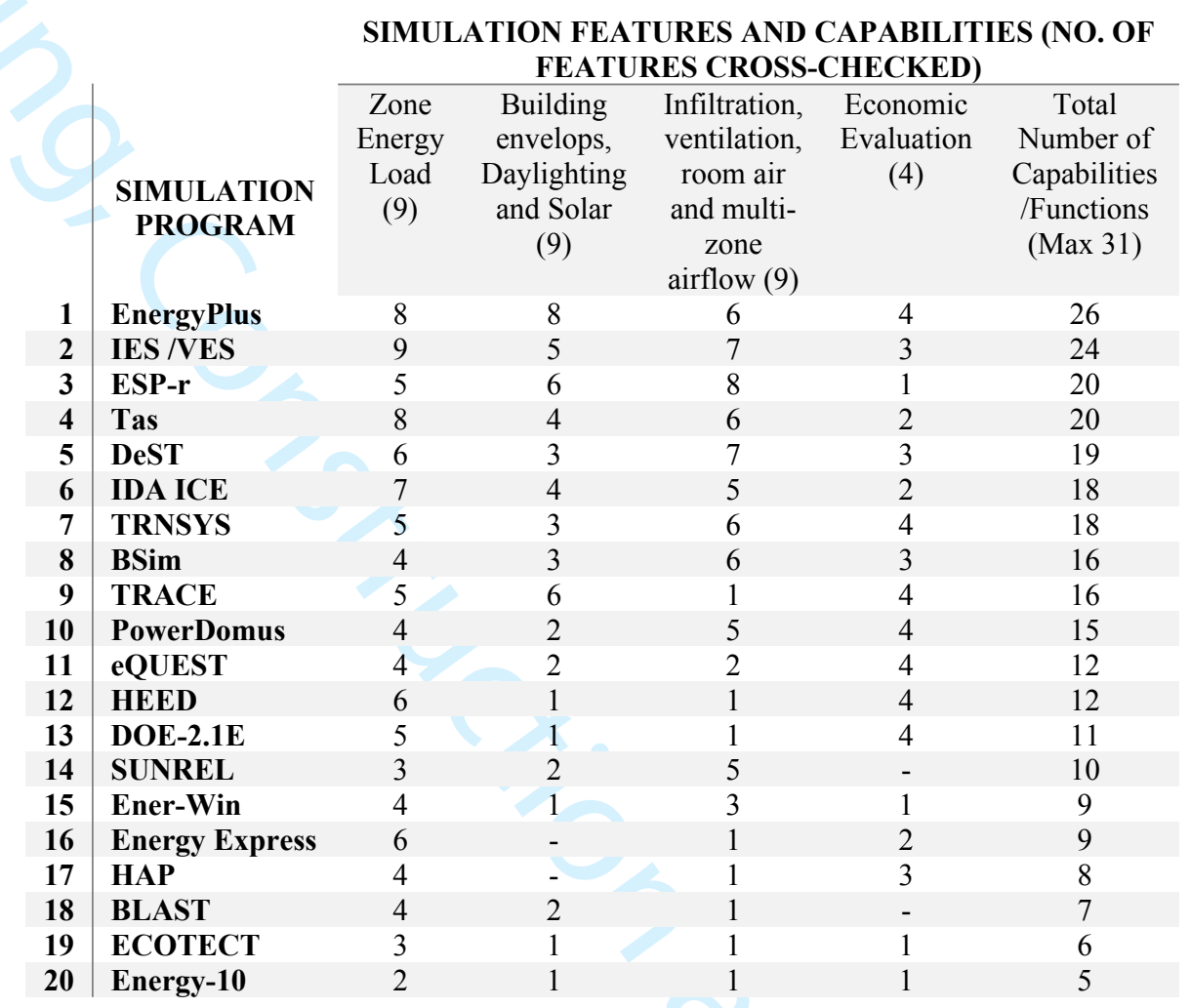

EnergyPlus has the ability of simulating the main energy consuming elements within buildings, associated with the heating, cooling, lighting, fans, pumps, bumbling/ water drainage utilities and any specific equipment, specified by the user. The simulation of energy consumed by buildings rely on the heat balance laws, governed by the geometry of its surfaces and the defined materials of those surfaces ("EnergyPlus: Getting Started Manual", 2018). Further, the calculations are influenced by the atmospheric conditions, the shading from surroundings and the daylight hours. The energy spent by a building is to control the inside conditions against the external influences, subject to the interconnections of the surface in between, the boundary conditions, conduction, convection, radiation, and mass transfer effects. For the air heat balance simulation, mass streams such as ventilation air, exhaust air, and infiltration are accounted for their direct convective heat gains considering a multizone airflow, infiltration, indoor contaminant, and ventilation calculations ("EnergyPlus: Getting Started Manual", 2018).

\section{Methodology}

In this paper the geometry is defined as a variable. The volume and size of floor areas are constant, but the floor area's aspect ratio can vary between a square to a rectangle, being the most typical shape of buildings in Kuwait and offering maximum area utilisation. At the early stage of a building's design, the envelope's geometry definition can provide broad guidance on how buildings consume energy, corresponding to the specific climate of Kuwait. The aim is to investigate the significance of buildings envelop design with the specific climate characteristics; where the seasonal weather is characterised by extreme and long hot summer and a short mild cold in winter (MOE\&W, 2019). The simulation of buildings' energy performances is performed using EnergyPlus, to calculate the different aspect of energy consumption for the different building's envelopes. Compared with the previous efforts using buildings' energy simulations, this work is not only focused on finding the optimum designs. The analysis is based on the simulation of every building case individually, to understand and demonstrate the buildings energy consumption's behaviour while maintaining a standard comfort level. The thermal 
comfort of users is achieved by sustaining the indoor thermal condition as specified in the design, to facilitate the user's operations. The methodology is explained with the definition of building envelop variables, parameters, and the simulation process of these components to obtain the performance results:

\subsection{Building envelope variables and parameters}

To use the simulation results of buildings' energy consumption for analysing the effects of specific variables on the overall buildings' energy performance, a clear definition of the buildings' variables and parameters is required. The chosen variables for this study are the building's orientation, the aspect ratio of the building's floor area and the window to wall ratio. The variance in the aspect ratio will directly result in change with the buildings' compactness, as the elevation, the volume and the size of the floor areas of the buildings defined as constants. The change in surface area of the buildings and how "compact" they become a function of the change in the width and the length (aspect ratio) of the floor plans. The ranges are chosen to be discrete values, offering a chance for analysing in depth the energy consumption differences between each case, shown in Table-2. Using Latin Hyper Cube (Sheikholeslami and Razavi, 2017) sampling to generate 80 building geometries, the orientation, compactness and the window to wall ratio are varied. Figure-3 shows the range of variance for the orientation and compactness variables. In order to evaluate these specific variables, all other building design and operating elements must be constant, enlisted here as building parameters. The envelope parameters are the number of floors (3), floors height (4 meter each), the floor area $\left(400 \mathrm{~m}^{2}\right)$ and the structural materials (selected from simulator's built-in template). The operation parameters are the indoor temperature settings, the building operating hours and building lighting system (Table-3).

Table 2 - Building envelope design variables

\begin{tabular}{clcc} 
& \multicolumn{1}{c}{ Variable } & Range & Unit \\
\hline 1 & Orientation & N, NE, E, SE \& S & Degrees \\
& $\begin{array}{l}\text { Aspect ratio/ } \\
\text { Compactness }\end{array}$ & $1: 1,1: 1.25,1: 1.5$, & Ratio \\
& $\begin{array}{l}\text { Window to } \\
\text { wall ratio }\end{array}$ & $20,40,60 \& 80$ & $\%$
\end{tabular}

Table 3 - Simulation Parameters Fixed in Each Simulation Run

\begin{tabular}{|c|c|c|c|}
\hline & Parameter & Value & Unit \\
\hline 1 & Weather Parameters & Kuwait City & - \\
\hline 2 & Number of floors & 3 & No. \\
\hline 3 & Floor area & 400 & $\mathrm{~m}^{2}$ \\
\hline 4 & Floor height & 4 & $\mathrm{~m}$ \\
\hline 5 & Building materials & $\begin{array}{l}\text { Project } \\
\text { construction } \\
\text { template }\end{array}$ & $\begin{array}{l}\text { Standard } \\
\text { Template }\end{array}$ \\
\hline 6 & HVAC operating system & $\begin{array}{l}\text { Fan coil unit } \\
\text { (4-Pipe), Air } \\
\text { cooled } \\
\text { chiller }\end{array}$ & $\begin{array}{l}\text { Standard } \\
\text { Template }\end{array}$ \\
\hline 7 & $\begin{array}{l}\text { HVAC heating temp. } \\
\text { setting }\end{array}$ & $\begin{array}{c}\text { Set back T } \\
12^{\circ} \mathrm{C} \text {, set } 20^{\circ} \\
\mathrm{C}\end{array}$ & Degree C \\
\hline 8 & $\begin{array}{l}\text { HVAC cooling temp. } \\
\text { setting }\end{array}$ & $\begin{array}{c}\text { Set back T } \\
25^{\circ} \mathrm{C} \text {, set } 22^{\circ} \\
\mathrm{C}\end{array}$ & Degree C \\
\hline 9 & building operating hours & $\begin{array}{c}\text { Generic } \\
\text { Office Area }\end{array}$ & $\begin{array}{l}\text { Standard } \\
\text { Template }\end{array}$ \\
\hline
\end{tabular}




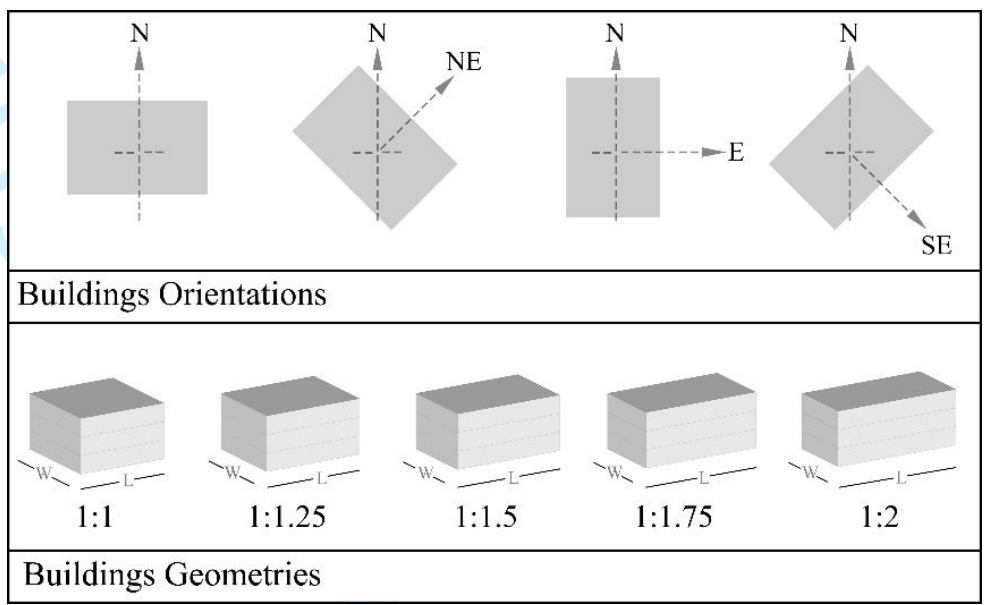

Figure 3 - Simple Representation of Orientation and Geometry Variance

The geometry of the building is varied with a constant floor area and building's height $(\mathrm{H})$. The length (L) and width (W) of each building of the 5 building forms shown in Figure-3 are calculated while maintaining the floor area at $400 \mathrm{~m}^{2}$. The initial building floor area is a square, with equal length and width $\left(L_{1}=W_{1}=20\right)$. Then the geometry is altered, solving for (L) and (W) with the initial condition of a fixed floor area at each of the aspect ratios:

$$
W_{2} / L_{2}=1 / 1.25, W_{3} / L_{3}=1 / 1.5, W_{4 / L_{4}}=1 / 1.75 \text { and } W_{4 / L_{4}}=1 / 2
$$

With that, the volume (V) remains constant within all buildings' forms. However, the variance in (L) and (W) have an impact on the buildings' surface areas (SA) considering the linear relationship between $(\mathrm{L})$ and $(\mathrm{W})$ in calculating a shape's parameter, and the non-linear relationship between (L) and $(\mathrm{W})$ in calculating the shape's volume.

$$
V=H W L, S A=H(2 W+2 L)
$$

The maximum difference in building's external surface area (walls and roof) while varying its geometry is about $6 \%$, between the most compact floor plan (square) and the least compact floor plan (rectangular form with a 1:2 aspect ratio). Other design components are chosen with fixed construction materials, selected from the built-in template within the simulation software. Hence, the differences in construction materials' quantities (at each window to wall ratio) are set to be limited (less than 6\%). Accordingly, the analysis explores the patterns and energy loads distributions that are mostly consumed to balance the thermostatic conditions between what is within the building's envelope and the external environmental elements. The output obtained is set to be the first step in exploring energy saving potentials that are specific to the selected region and explore how the guidance for energy optimisation may differ from the previous works, influenced by the characteristics of different climate condition.

\subsection{Simulating energy patterns based on the building's envelope design variables}

In this paper, EnergyPlus is used for simulating the building's yearly energy consumption. The software has an open-source scripting access, as well as multiple supporting systems that can facilitate the input process with template libraries and drafting interface ("EnergyPlus: Getting Started Manual", 2018). In connection to EnergyPlus, DesignBuilder is employed as the building drafting and area classification platform. DesignBuilder has pre-set data for building characteristics such as building materials, operating schedules, occupancy heat gains, heating/cooling systems. The availability of these defined parameters makes the process of analysing the contribution of the set of variables simpler, while calculating the energy consumed in each case is a result of a single variation at a time. The HVAC operating system selected is a Fan coil unit (a commonly used HVAC system in the selected region) 
and the operating temperatures setting are detailed in Table 3. In EnergyPlus, the energy consumed through interior/exterior equipment (including lighting) and water facilities (such as plumbing) are mostly governed by the building's floor area and the occupancy rates/hours. Hence, by fixing the buildings floor areas, the zones/building volume and the occupancy rates/hours, the energy consumed by interior/exterior equipment and water facilities can be assumed to be constants in the different buildings' geometry and orientation configurations.

To calculate the air system output (Q) for cooling or heating, the simulation considers four heat transfer functions as per the following equation:

$$
\mathrm{Q}=\sum_{i=1}^{\mathrm{Nsl}} \mathrm{SL}_{i}+\sum_{i=1}^{\text {Nsurfaces }} Z S_{i}+\sum_{i=1}^{\text {Nzones }} Z M_{i}+I
$$

where, SL represent the convective internal loads from each source inside a zones (equipment and/or occupants), ZS represent the convective heat transfer from the surfaces (internal/external walls and windows) defining a zone, ZM is the heat transfers due to inter-zones air mixing and I is the heat transfer due to infiltration of outside air in to a zone. Given the constant number of zones defined for all the buildings analyzed, the constant number of internal loads within the zones and the constant number of infiltration points, ZS is the only variable with direct correlation to the change in the surface area of the zones and is calculated using the following equation:

$$
Z S_{i}=\mathrm{H}_{\mathrm{i}} \mathrm{A}_{\mathrm{i}}\left(\Delta \mathrm{T}_{i}\right)
$$

where, $\mathrm{H}$ is the height of the zone, $\mathrm{A}$ is the floor area of the zone and $\Delta \mathrm{T}$ is the temperature difference between the surfaces' temperature and the air within the zone's temperature. EnergyPlus's algorithm is based on time steps, to update the zone's temperature using a predictor-corrector approach (Mazumder, 2016). As the surfaces composition is changing (varying the window to wall ratio), $\Delta \mathrm{T}$ 's rate of changing differs, explaining the focus of this paper on the defined three envelope variables.

\section{Results and Analysis}

Starting with the patterns of the building's yearly energy consumption, at the different orientations, Figure-4 (A, B, C and D) summarises the 80 buildings' behaviours when the window to wall ratios are at $20 \%, 40 \%, 60 \%$ and $80 \%$, respectively. The vertical-axis is the yearly net energy consumed in KW; While, the horizontal-axis represent the orientation of the buildings, starting with the longer span facing North; then North-East, East, South-East and South (equivalent to North due to buildings' symmetry). The different lines correspond to the buildings' aspect ratios at 1:1, 1:1.25, 1:1.5, 1:1.75 and 1:2. The shapes appear consistent across the four plots representing the buildings at different window to wall ratios. The behaviour mainly corresponds to the envelopes' surface areas and the amount of solar radiation contributing to the heat gains and losses. From the patterns in Figure-4, it's clear that buildings with the longer span facing East always consume energy at the highest rates in every aspect ratio other than one. Due to symmetry, when the aspect ratio is 1:2 (square shaped floor plan), North-East and South-East facing buildings consume more energy than when its facing North/East. 
These results demonstrate that in most configurations, while varying the orientation and aspect ratios, the more compacted the buildings layouts are, the lower energy the building will consume. This is a result of the heating and cooling loads, exerted to balance the climate contribution toward the

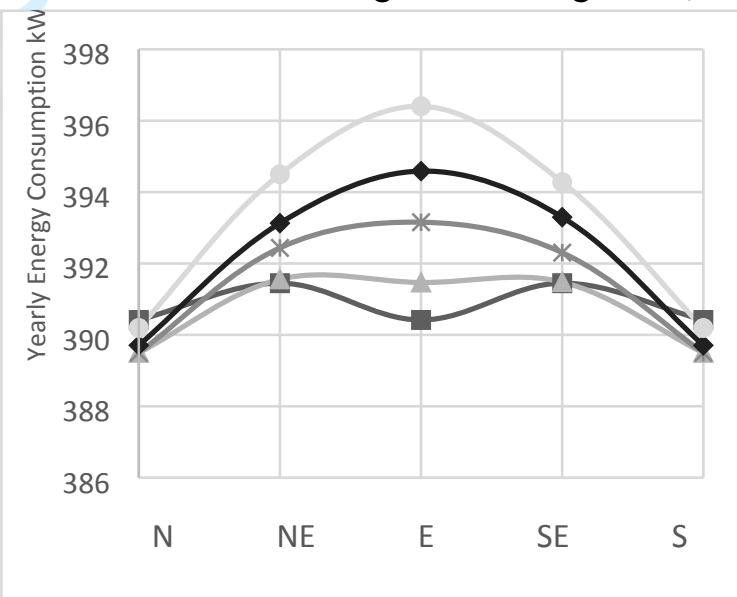

(4-A) - $20 \%$ window to wall ratio

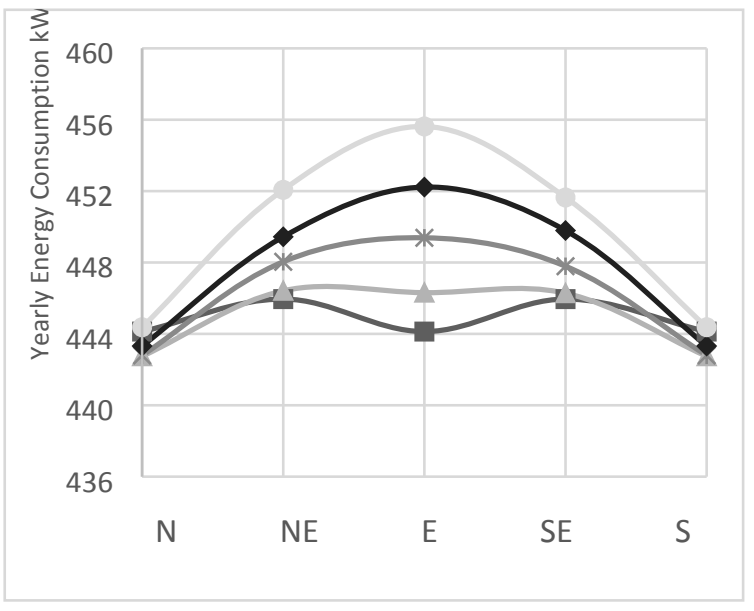

(4-B) $-40 \%$ window to wall ratio

building's heat gains/losses. The heat balance is simulated between the inside and the outside of the building through the surfaces exposed to the weather (roofs, walls, and windows). When the buildings' longer spans are facing North, the behaviours trends are very different in their pattern than any other orientation. Figure-5 (A, B, C, and D) show the energy consumption patterns of North facing buildings at $1: 1,1: 1.25,1: 1.5,1: 1.75$ and $1: 2$ aspect ratios with $20 \%, 40 \%, 60 \%$ and $80 \%$ window to wall ratios.

The analysis indicates that for buildings while their longer span is facing North, buildings of aspect ratios between 1:1.25 and 1:1.5 have energy consumption rates that can be identified as minimum. Moreover, the simulated values of the building's energy consumption with aspect ratios of 1:1 and 1:2 are the highest and close to each other when they face North. All other orientations (Figure 6) have an ascending pattern of energy consumption with the lowest value attributed to the aspect ratio with the highest compactness (1:1). The amount of energy consumed and the convexity changes as the window to wall ratios are increasing.

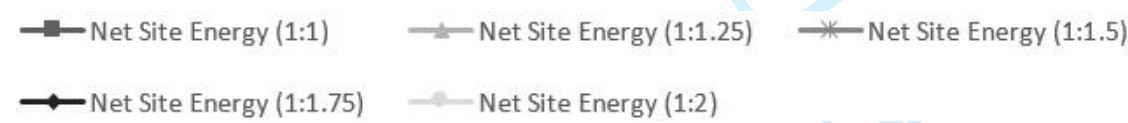

Figure $4[(A, B, C$ and $D]-$ Net energy consumptions for North facing buildings at $(20 \%, 40 \%, 60 \%$ and $80 \%)$ window to wall ratios

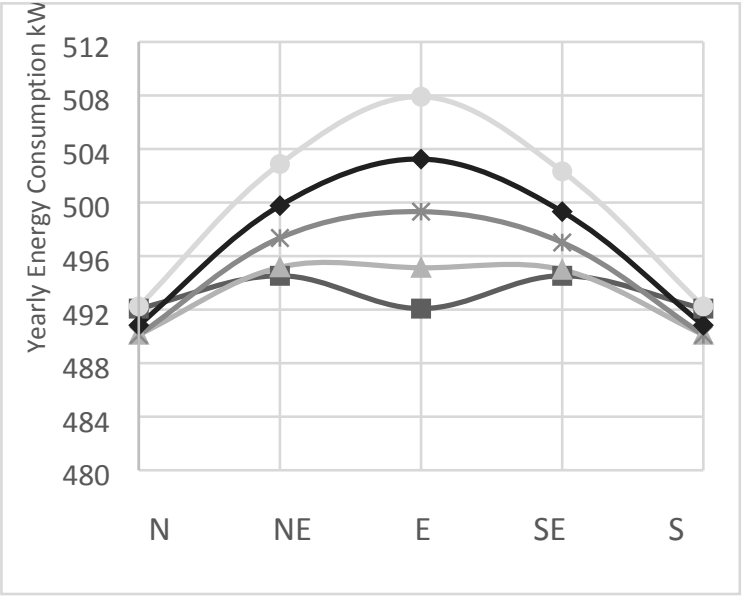

(4-C) $-60 \%$ window to wall ratio

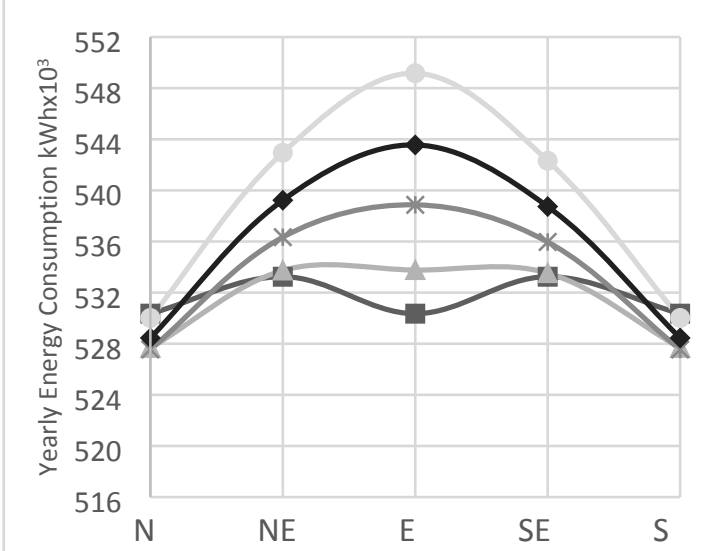

(4-D) - $80 \%$ window to wall ratio 


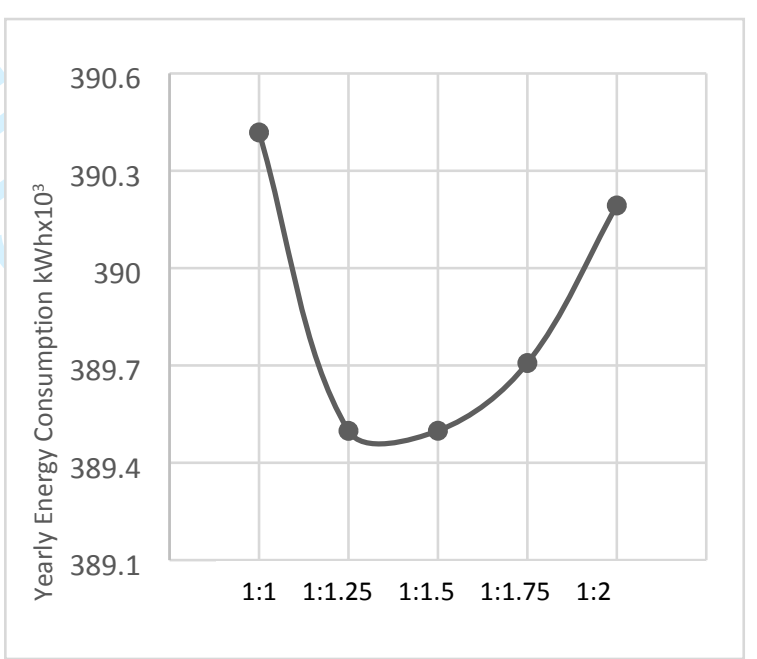

(5-A) - $20 \%$ window to wall ratio

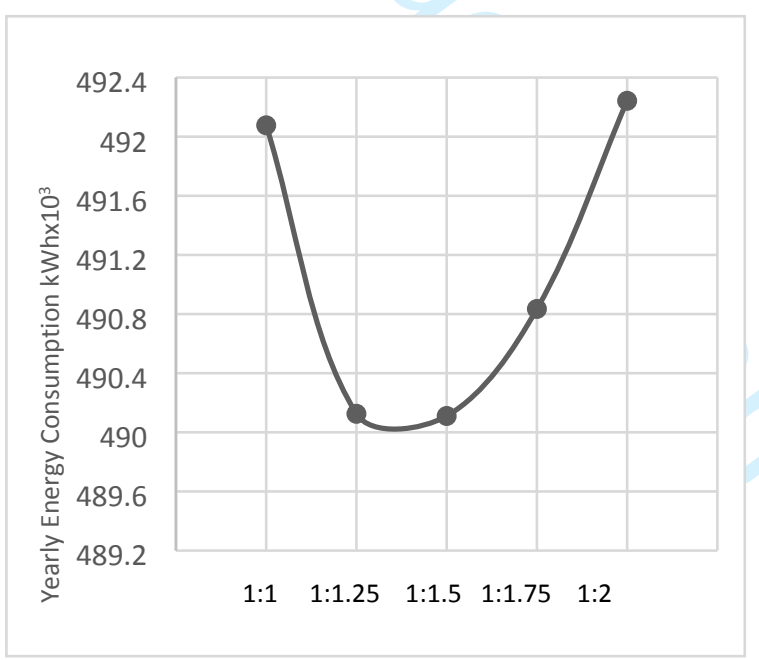

(5-C) - 60\% window to wall ratio

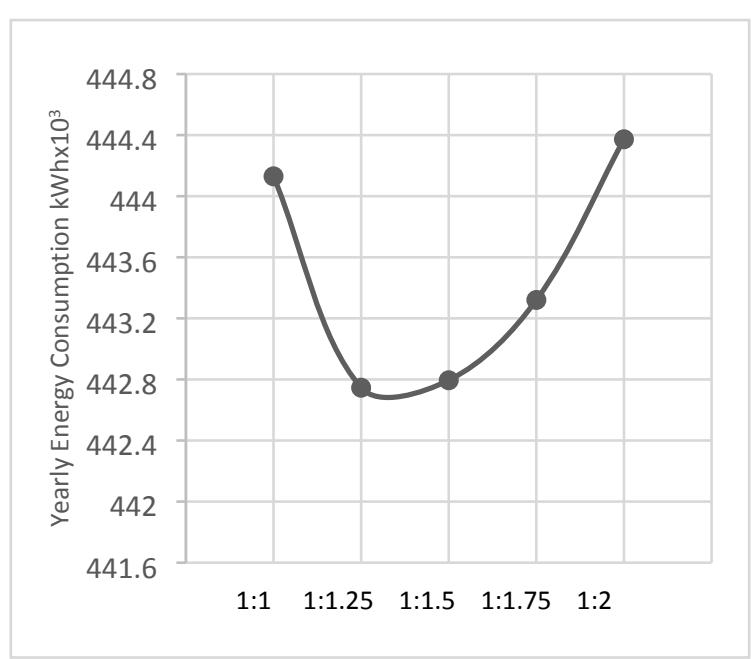

(5-B) - 40\% window to wall ratio

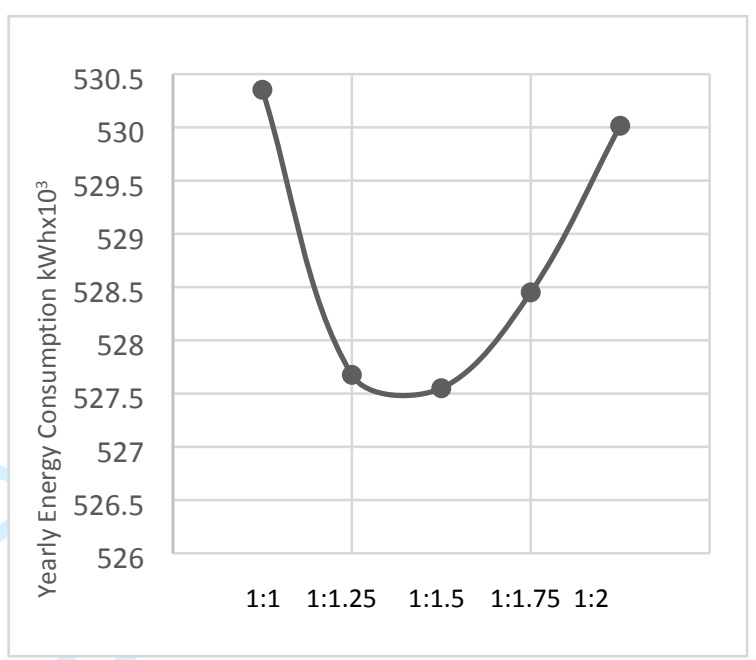

(5-D) - $80 \%$ window to wall ratio

Figure 5 [A, B, C and D] - Net energy consumptions, varying the orientation and compactness at $(20 \%, 40 \%, 60 \%$ and $80 \%)$ window to wall ratios
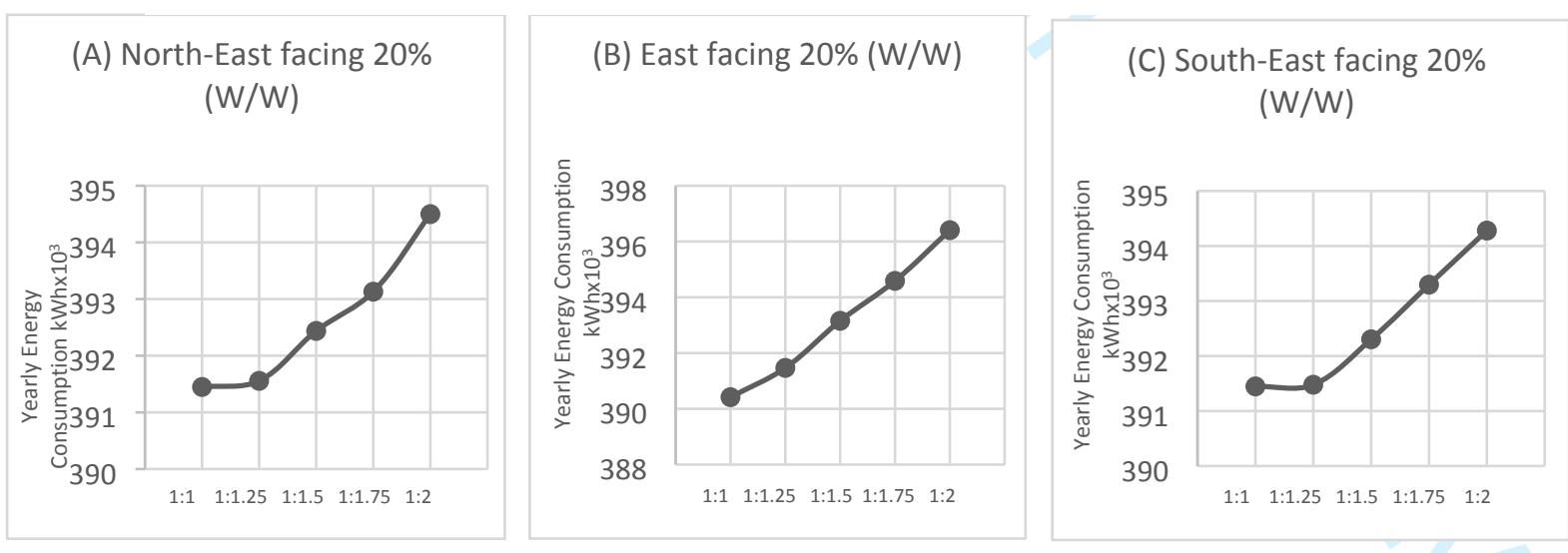
(D) North-East facing 40\% (W/W)

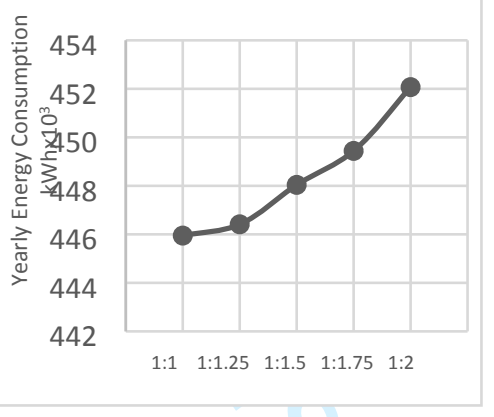

(G) North-East facing 60\% (W/W)

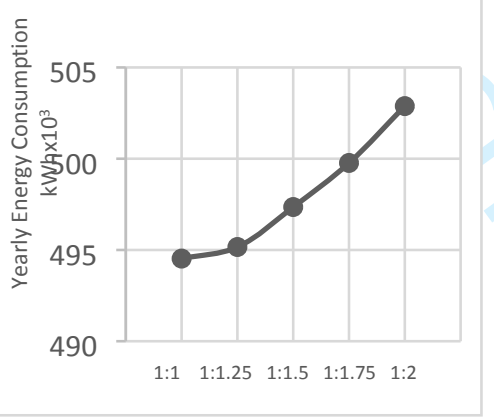

(J) North-East facing $80 \%$ (W/W)

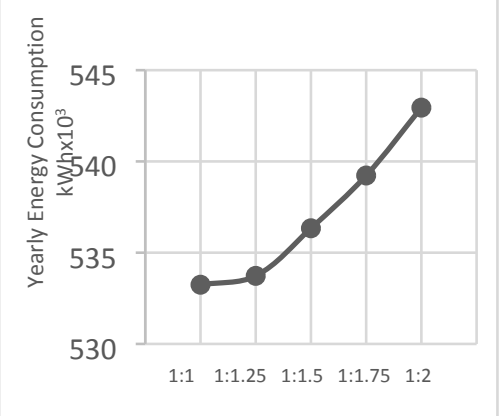

(E) East facing 40\% (W/W)

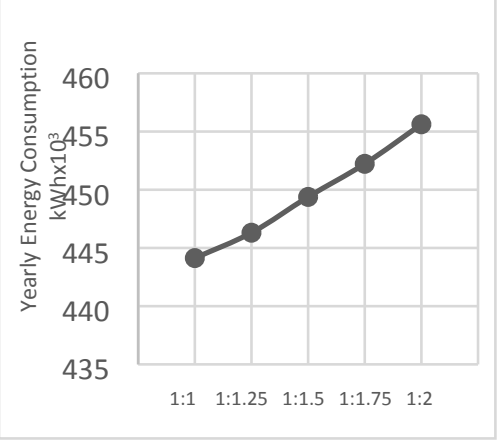

(H) East facing $60 \%(\mathrm{~W} / \mathrm{W})$

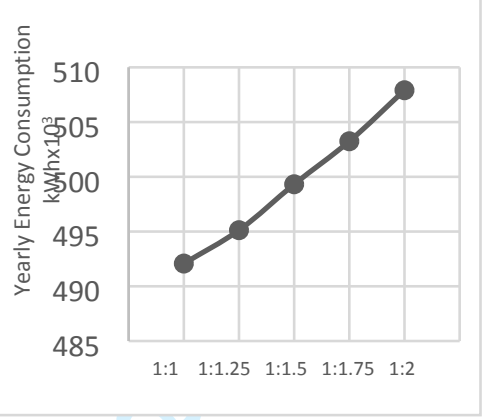

(K) East facing $80 \%(\mathrm{~W} / \mathrm{W})$

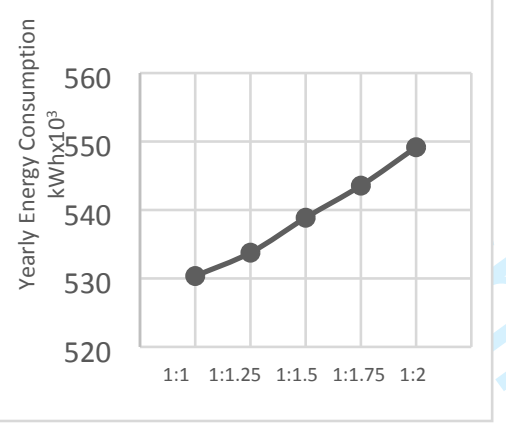

(F) South-East facing 40\% (W/W)

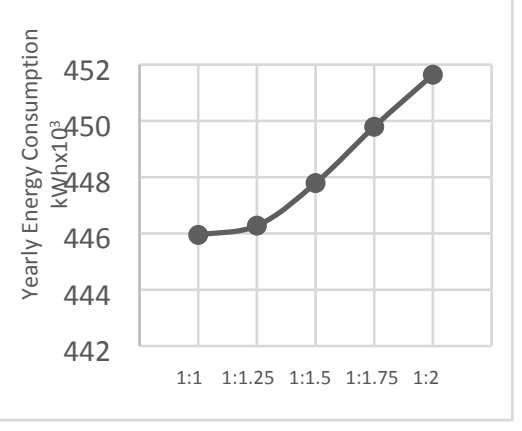

(I) South-East facing $60 \%$ (W/W)

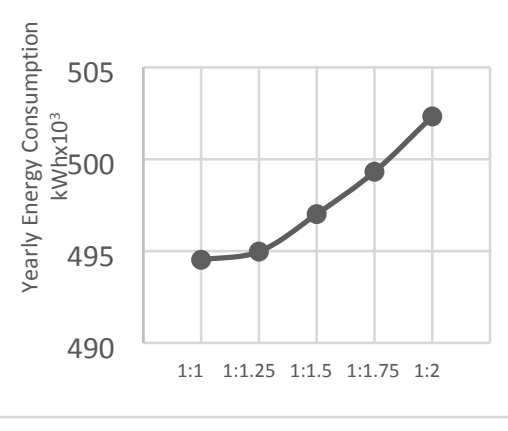

(L) South-East facing $80 \%$ (W/W)

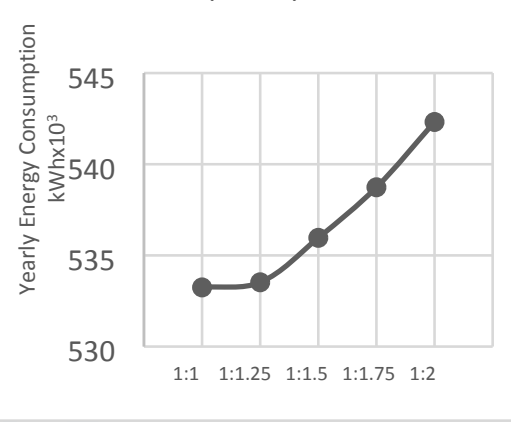

Figure $6[A, B, C, D, E, F, G, H, I, J, K$ and $L]-$ Compactness ratios vs. window to wall ratios at different orientation

The output of the simulation also details energy consumption data concerning internal lighting loads, water heating loads, cooling/heating peak loads as well as estimates for water consumption. Across all buildings, the water consumption and the water heating loads are almost constant. At each window to wall ratio, it's observed that the lighting loads and water heating loads are constant while varying the orientation, with variances less than $0.5 \%$ at the different compactness ratios. A slight advantage is for buildings with 1:2 aspect ratio form over every other form.

Across the different window to wall ratios, buildings with $20 \%$ window to wall ratio recoded peak cooling loads less than buildings with $80 \%$ window to wall ratio with a $31 \%$ difference. However, buildings with $20 \%$ window to wall ratio recoded peak heating loads more than buildings with $80 \%$ window to wall ratio with a $28 \%$ difference. HVAC systems are generally designed to operate with capacities capable of handling the peak heating and cooling demands. Different window to wall ratios 
results in different peak loads. The results show that the variance in buildings' window to wall ratio, between $20 \%$ and $80 \%$, lead to a $30 \%$ increase in the HVAC system capacity requirement.

To validate the results, 20 new cases are simulated, for a building with $20 \%$ window to wall ratio while varying the orientation and compactness as specified in the methodology. The difference is that the size of the buildings has increased, from three floors with a $400 \mathrm{~m}^{2}$ floor area (Building A) to five floors with 2,500 $\mathrm{m}^{2}$ floor area (Building B). Figure-7 shows the scale difference between the buildings models used in the detailed analysis (Building A) and the results validation (Building B), including the overall volume difference:

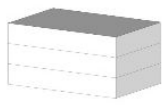

Building A

$$
400
$$$$
4,800
$$

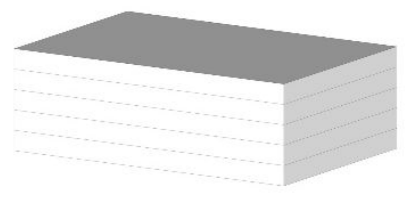

Building B

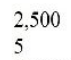

50,000

Figure 7- Simple visualization of scale difference (Analysis [Building A] vs. Validation [Building B])

This is to explain that the analysed patterns are not specific to the initial scale. For the new 20 cases, the buildings behave in a similar pattern as in the detailed analysis, with higher overall consumption rates. The buildings with aspect ratios between 1:1.25 and 1:1.75 while their longer spans are facing North, perform better than the most compact form (1:1 aspect ratio). In all other orientations, the compact form performs better. The increase in those yearly energy rates is attributed to the fact that the new results are for buildings almost ten times bigger than the original scale initially used.

\section{Discussion}

Our analysis reveals that the window to wall ratio variable is the most critical factor, in that it has major impact on the total building's energy consumption and peak load. The overall lowest energy consumption configuration has a $20 \%$ window to wall ratio, with a 1:1.25 floor plan's aspect ratio while the longer span is facing North. The differences in energy consumption, between each case and the least energy consumption configuration, due to changing the window to wall ratio at the different aspect ratios of $1: 1.25,1: 1.5,1: 1.75$ and $1: 2$ are $37 \%, 38 \%, 39 \%$ and $40 \%$, respectively.

With the square form (1:1 aspect ratio), due to its symmetry, North and East facing orientations have the similar values. In that form, the yearly energy consumption is a higher at the North-East and South-East orientations. The variance due to the increase of window to wall ratios at the different orientations is almost the same at $36 \%$.

While the relationship between building's energy consumption and the window to wall ratios was addressed in (Baglivo et al., 2017; Ferrara et al., 2015; Gero et al., 1983), this study quantifies the regional significance of the window to wall composition design on the net energy consumption and the cooling/heating systems' capacities design. Form the peak loads' results, the variance in the cooling and heating system's capacities can vary within a $30 \%$ range, at the different window to wall ratios analysed. This value helps the building's user/designer in trading off the advantages of increasing natural light and the corresponding increase in the system's capacity, leading to increases in the cost of HVAC system and the yearly energy consumed.

The change in orientation, at the defined different degrees of compactness (floor plan's aspect ratios) can lead to variances in the energy consumption up to $1.8 \%, 2.9 \%, 3.6 \%$ and $4.1 \%$ at window to 
wall ratios of $20 \%, 40 \%, 60 \%$ and $80 \%$ respectively. The most consuming configuration being at $1: 2$ floor plan aspect ratio, while the longer span is facing East at every window to wall ratio. When the floor plan's shape is square, North and East facing orientations have the similar values, consuming less energy than North-East and South-East orientations. The results in this paper support the general notion in (Rashdi and Embi, 2016), that buildings with similar geometry, when the longer axis is facing North, they would perform better than any other orientation, leading to the least energy usage for cooling. Moreover, in [12], their simulation gives guidance suggesting that lower surface-to-volume ratios (the more compact the building's form is) lead to lower cooling loads consumption. However, in contrast with their results, our results show that while the building's longer spans are facing North, the buildings with floor plan's aspect ratios between 1:1.25 and 1:1.5 have lower energy consumption loads than the most compacted geometry (1:1, square floor plan). Although our simulation considers the cooling loads as well as the heating loads associated with Kuwait's climate, when the cooling loads are isolated, the conclusion remains consistent in favour of aspect ratios between 1:1.25 and 1:1.5. This contrast in results seem to validate that the climate of choice is key in developing design guidance, aiming to improve the buildings' energy performance aspects.

Furthermore, our analysis shows that the behaviour between the compact design of a square floor aspect ratio $(1: 1)$ and the rectangular floor design of $1: 2$ aspect ratio is of significance. Compared with the analysis done in (Aksoy and Inalli, 2006), they chose to study the energy performance while varying the geometry, selecting only two ratios in their simulation $(1: 1$ and 1:2). Based on that definition, their conclusion was that the compact design (1:1) has a lower heating demand based on their region's climate, which is contradictory with the findings in this paper, considering Kuwait's climate. The simulated heating loads indicate that the square form consume more energy than other forms when their longer spans are facing North or North-East. The results also show that buildings with aspect ratios between 1:1.25 and 1:1.75 have lower cumulative cooling/heating loads than the most compacted form (square) and rectangular buildings with 1:2 aspect ratio. Further to what they have simulated, our analysis show that geometries between those two ratios have better performance.

Finally, Standards such as the International Energy Conservation Code 2018, ASHRAE Standard 90.1, GB50189 Design Standard for Energy Efficiency in Public Buildings and the National Construction Code (NCC) are some of the measures used in major countries such as USA, China and Australia (Ma and Airah, 2017). Limitations to the window to wall ratio are specified differently in these standards, some recommended that the window to wall ratio must not exceed $30 \%$, while others recommended the window to wall ratio must not exceed $40 \%$. Exceptions to exceed those recommended values are also explained, influenced by the type of glazing used. These standards combined with the results here can help directing local institutions within the GCC and Kuwait to set specific/regional recommendations.

\section{Conclusion}

The lack of regional publications addressing the effect of buildings' envelope design on energy consumption is the main derive for this research. This paper investigated three early-design variables and analysed their influence over the yearly energy consumption and peak values, simulated under the climate condition of Kuwait. In our simulation, the buildings' orientation, compactness, and window to wall ratios are varied, and it was found that buildings while their longer span facing North are most efficient in energy consumption. Unlike the findings reported in pervious literature, simulated at different regions, the most compact form is not the optimum in the specific region of Kuwait, considering the specific geometry/orientations studied. When the longer span is facing North, rectangular buildings of floor plans aspect ratios between 1:1.25 and 1:1.5 consume less energy than any other configurations including the most compacted (1:1 floor plan aspect ratio) form. 
Designers' decisions on buildings' window to wall ratio has the potential for net energy consumption savings up to $40 \%$; Furthermore, based on the peak loads calculation, the HVAC system capacity can be reduced by $30 \%$. The maximum differences attributed to the change in orientation or in compactness are less than 5\%, at the different window to wall ratios analysed. Access to such details is of a great importance in guiding designers, making early design decisions specific to those variables for buildings in Kuwait.

The climate characteristics are one of the major factors in understanding the thermal behaviour of buildings. Further work, investigating the variances of similar parameters discussed in this paper at different geographical locations can be of a great value as well. This is informative as it shows the change in energy patterns as the climate conditions change.

\section{References}

Aksoy, U.T. and Inalli, M. (2006), "Impacts of some building passive design parameters on heating demand for a cold region", Building and Environment, Vol. 41 No. 12, pp. 1742-1754.

Al-Awadhi, J.M. and AlShuaibi, A.A. (2013), "Dust fallout in Kuwait city: Deposition and characterization", Science of the Total Environment, Elsevier B.V., Vol. 461-462, pp. 139-148.

Albatayneh, A., Alterman, D., Page, A. and Moghtaderi, B. (2018), "Renewable energy systems to enhance buildings thermal performance and decrease construction costs", Energy Procedia, Elsevier B.V., Vol. 152, pp. 312-317.

Baglivo, C., Congedo, P.M., Di Cataldo, M., Coluccia, L.D. and D'Agostino, D. (2017), “Envelope design optimization by thermal modelling of a building in a warm climate", Energies, Vol. 10 No. 11, available at:https://doi.org/10.3390/en10111808.

Budaiwi, I. and Abdou, A. (2013), "HVAC system operational strategies for reduced energy consumption in buildings with intermittent occupancy: The case of mosques", Energy Conversion and Management, Elsevier Ltd, Vol. 73, pp. 37-50.

Cassol, F., Schneider, P.S., França, F.H.R. and Silva Neto, A.J. (2011), "Multi-objective optimization as a new approach to illumination design of interior spaces", Building and Environment, Elsevier Ltd, Vol. 46 No. 2, pp. 331-338.

Choi, J.H. (2017), "Investigation of the correlation of building energy use intensity estimated by six building performance simulation tools", Energy and Buildings, Elsevier B.V., Vol. 147, pp. 14 26.

Crawley, D.B., Hand, J.W., Kummert, M. and Griffith, B.T. (2008), "Contrasting the capabilities of building energy performance simulation programs", Building and Environment, Vol. 43 No. 4, pp. 661-673.

Delgarm, N., Sajadi, B. and Delgarm, S. (2016), "Multi-objective optimization of building energy performance and indoor thermal comfort: A new method using artificial bee colony (ABC)", Energy and Buildings, Elsevier B.V., Vol. 131, pp. 42-53.

Delgarm, N., Sajadi, B., Delgarm, S. and Kowsary, F. (2016), "A novel approach for the simulationbased optimization of the buildings energy consumption using NSGA-II: Case study in Iran", Energy and Buildings, Elsevier B.V., Vol. 127, pp. 552-560.

Dodoo, A., Tettey, U.Y.A. and Gustavsson, L. (2017), "Influence of simulation assumptions and input parameters on energy balance calculations of residential buildings", Energy, Elsevier Ltd, Vol. 120, pp. 718-730.

Elkilani, A. and Bouhamra, W. (2001), "Estimation of optimum requirements for indoor air quality and energy consumption in some residences in Kuwait", Environment International, Vol. 27 No. 6, pp. 443-447. 
Enerdata. (2017a), COUNTRY ENERGY REPORT QATAR.

Enerdata. (2017b), COUNTRY ENERGY REPORT, UAE.

Enerdata. (2017c), COUNTRY ENERGY REPORT, KUWAIT.

Enerdata. (2018a), COUNTRY ENERGY REPORT, BAHRAIN.

Enerdata. (2018b), COUNTRY ENERGY REPORT, OMAN.

Enerdata. (2018c), COUNTRY ENERGY REPORT, KSA.

“EnergyPlus: Getting Started Manual”. (2018), EnergyPlus, U.S. Department of Energy, U.S.A.

Ferrara, M., Filippi, M., Sirombo, E. and Cravino, V. (2015), “A simulation-based optimization method for the integrative design of the building envelope", Energy Procedia, Elsevier B.V., Vol. 78, pp. 2608-2613.

Fesanghary, M., Asadi, S. and Geem, Z.W. (2012), "Design of low-emission and energy-efficient residential buildings using a multi-objective optimization algorithm", Building and Environment, Elsevier Ltd, Vol. 49 No. 1, pp. 245-250.

Fong, K.F., Hanby, V.I. and Chow, T.T. (2006), "HVAC system optimization for energy management by evolutionary programming", Energy and Buildings, Vol. 38 No. 3, pp. 220-231.

Gero, J.S., D’Cruz, N. and Radford, A.D. (1983), "Energy in context: A multicriteria model for building design”, Building and Environment, Vol. 18 No. 3, pp. 99-107.

Hamdy, M., Hasan, A. and Siren, K. (2011), “Applying a multi-objective optimization approach for Design of low-emission cost-effective dwellings", Building and Environment, Elsevier Ltd, Vol. 46 No. 1, pp. 109-123.

Huang, Y. and Niu, J.L. (2016), “Optimal building envelope design based on simulated performance: History, current status and new potentials", Energy and Buildings, Elsevier B.V., Vol. 117, pp. 387-398.

Imam, S., Coley, D.A. and Walker, I. (2017), "The building performance gap: Are modellers literate?”, Building Services Engineering Research and Technology, Vol. 38 No. 3, pp. 351-375.

Lartigue, B., Lasternas, B. and Loftness, V. (2014), "Indoor and Built Multi-objective optimization of building envelope for energy consumption and daylight", Vol. 23 No. 1, pp. 70-80.

Ma, Y. and Airah, S. (2017), "Comparison of Building Energy Codes in Australia, United States and China for Australian Commercial Building Energy Conservation”, No. February 2018, pp. 1-15.

Marks, W. (1997), "Multicriteria optimisation of shape of energy-saving buildings", Building and Environment, Vol. 32 No. 4, pp. 331-339.

Mazumder, S. (2016), "Solution to a System of Linear Algebraic Equations", Numerical Methods for Partial Differential Equations, Elsevier, pp. 103-167.

Mirsadeghi, M., Cóstola, D., Blocken, B. and Hensen, J.L.M. (2013), "Review of external convective heat transfer coefficient models in building energy simulation programs: Implementation and uncertainty", Applied Thermal Engineering, Elsevier Ltd, Vol. 56 No. 1-2, pp. 134-151.

MOE\&W. (2019), Statistical Year Book, Electrical Energy.

Nguyen, A.T., Reiter, S. and Rigo, P. (2014), “A review on simulation-based optimization methods applied to building performance analysis", Applied Energy, Elsevier Ltd, Vol. 113, pp. 10431058.

Park, J., Kim, T. and Lee, C. sung. (2019), “Development of thermal comfort-based controller and 
potential reduction of the cooling energy consumption of a residential building in Kuwait", Energies, Vol. 12 No. 17, available at:https://doi.org/10.3390/en12173348.

Rashdi, W.S.S.W.M. and Embi, M.R. (2016), "Analysing Optimum Building form in Relation to Lower Cooling Load", Procedia - Social and Behavioral Sciences, The Author(s), Vol. 222, pp. 782-790.

Sebzali, M.J. and Rubini, P.A. (2007), "The impact of using chilled water storage systems on the performance of air cooled chillers in Kuwait", Energy and Buildings, Vol. 39 No. 8, pp. 975984.

Sheikholeslami, R. and Razavi, S. (2017), "Progressive Latin Hypercube Sampling: An efficient approach for robust sampling-based analysis of environmental models", Environmental Modelling \& Software, Vol. 93, pp. 109-126.

Simões, N., Prata, J. and Tadeu, A. (2014), "Contribution of linear thermal bridges to the overall thermal performance of the building envelope: Dynamic analysis", WIT Transactions on the Built Environment, Vol. 142, pp. 321-332.

Tiene, S., Bragadin, M.A. and Ballabeni, A. (2018), “A Genetic Algorithm-based approach for Project Management and developed design of construction”, Techne, Vol. 16, pp. 131-141.

Ward, R., Choudhary, R., Heo, Y. and Rysanek, A. (2016), "Exploring the impact of different parameterisations of occupant-related internal loads in building energy simulation", Energy and Buildings, Elsevier B.V., Vol. 123, pp. 92-105.

Yu, W., Li, B., Jia, H., Zhang, M. and Wang, D. (2015), “Application of multi-objective genetic algorithm to optimize energy efficiency and thermal comfort in building design", Energy and Buildings, Elsevier B.V., Vol. 88, pp. 135-143.

Zhou, X., Hong, T. and Yan, D. (2014), "Comparison of HVAC system modeling in EnergyPlus, DeST and DOE-2.1E”, Building Simulation, Vol. 7 No. 1, pp. 21-33.

Zhou, Y.P., Wu, J.Y., Wang, R.Z., Shiochi, S. and Li, Y.M. (2008), "Simulation and experimental validation of the variable-refrigerant-volume (VRV) air-conditioning system in EnergyPlus", Energy and Buildings, Vol. 40 No. 6, pp. 1041-1047. 